\title{
STRENGTH AND FRACTURE TOUGHNESS OF THE WELDED JOINTS MADE OF HIGH-STRENGTH FERRITIC STEEL
}

\author{
Ihor DZIOBA*, Tadeusz PALA*, llkka Valkonen** \\ *Department of Machine Design Fundamentals, Kielce University of Technology, \\ Aleja 1000-lecia Państwa Polskiego, 7, 25-314 Kielce, Poland \\ ${ }^{*}$ Rautaruukki Oyj, R\&D Centre, Harvialantie 420, Hameenlinna, Finland \\ pkmid@tu.kielce.pl, tadeusz.pala@gmail.com, Q0782.rrsteel@ruuki.com
}

\begin{abstract}
The paper presents experimental results of the characteristics of strength and fracture toughness of the material from the different zones of welded joints made of different participation of the linear welding energy. Strength characteristics and fracture toughness were determined in the weld material, in the area of fusion line, in the material of the heat affected zone and in the base material.
\end{abstract}

Key words: High-Strength Ferritic Steel, Welded Joints, Strength and Fracture Toughness Characteristics for Welded Joints Material

\section{INTRODUCTION}

In order to increase competitiveness and to meet the requirements that are specified by the customer, the companies produce steels with favorable operating parameters (Porter, 2006). These steels are characterized by properties of high strength, hardness, wear resistance. The high level properties of the steel can extend the life-time of components, reduce the frequency and cost of replacement parts to be used, which leads to increased safety during operation of the equipment.

To fully utilize and apply the high-strength ferritic steel in structures and mechanisms is necessary to take into account the issue of its weldability. Welded joints in terms of strength are places where there is a heightened risk of the occurrence of damage, due to the different microstructures of the material in the different zones of the joints (Tasak and Ziewiec, 2006), the presence of micro-defects and welding residual stress and the geometric factor, which causes the joint to be treated as a kind of stress concentrators (FITNET, 2008; Neimitz et al., 2008). Obtaining a proper strength of the welded joint, if the base material is high-strength steel, is a difficult task to accomplish. Technology selection and filler material should be provided, so that the material characteristics in all of zones of the welded joints, were similar to the base material characteristics.

This paper presents the results of experiments carried out on the material of two types of joints, made of high-strength ferritic steel S960QC, in which the welding process had different linear energy of welding $-0.7 \mathrm{~kJ} / \mathrm{mm}$ and $1.2 \mathrm{~kJ} / \mathrm{mm}$. The measurements of hardness, strength characteristics were determined and the fracture toughness critical value of the material from the different zones of welded joints.

\section{MATERIALS AND RESEARCH METHODS}

Joints are made of sheet metal with a thickness of $8 \mathrm{~mm}$ highstrength ferritic steel S960QC. Chemical composition is given in
Tab. 1. As a result of thermo-mechanical processing steel obtains fine-grained microstructure of bainite-martensite (Fig. 1a) with a hardness of $\geq 350 \mathrm{HV} 10$ and strength characteristics: $R_{\mathrm{e}} \geq 960$ $\mathrm{MPa}, R_{\mathrm{m}} \geq 1000 \mathrm{MPa}$. As a result of welding carried out with a linear speed of $1.2 \mathrm{~kJ} / \mathrm{mm}(A)$ and a linear speed of $0.7 \mathrm{~kJ} / \mathrm{mm}(B)$ in the welds was fine ferrite microstructure (Fig. 1b) and martensite (Fig. 1C). Hardness distributions were measured on the cross-section of the joint along the horizontal and vertical measuring lines (Fig. 2a) according to the Vickers's method at the load of $10 \mathrm{~N}$, with a frequency of every $1 \mathrm{~mm}$.

Tab. 1. Chemical composition (in mass \%)

\begin{tabular}{|c|c|c|c|c|c|c|c|c|c|c|c|}
\hline & $\mathbf{C}$ & $\mathbf{S i}$ & $\mathbf{M n}$ & $\mathbf{P}$ & $\mathbf{S}$ & $\mathbf{T i}$ & $\mathbf{C r}$ & $\mathbf{~ N i}$ & $\mathbf{M o}$ & $\mathbf{V}$ & $\mathbf{C u}$ \\
\hline $\begin{array}{c}\text { S960- } \\
\text { QC }\end{array}$ & 0.11 & 0.25 & 1.20 & 0.020 & 0.010 & 0.07 & $\begin{array}{c}\mathrm{CEV}=\mathrm{C}+\mathrm{Mn} / 6+(\mathrm{Cr}+\mathrm{Mo}+ \\
\text { V)/5+ }\end{array}$ \\
\hline
\end{tabular}

Strength characteristics of the tested joints were determined in the uniaxial tension test on a modernized testing machine UTS100 , equipped in the automated control system and results recording. Uniaxial tension test was carried out on the fivefold, flat specimens, cut out from the appropriate zones of the welded joint, along the weld axis (Fig. 2b). References from A1 to A4 correspond respectively to the specimens cut out from the weld material (WM), heat affected zone of the material at the fusion line (HAZFL), heat affected zone at the end of the normalization zone (HAZN), material at the end of the heat affected zone (HAZE) and base material (BM). During the uniaxial tension tests performance, $P$ force signals and extension of the measuring part of the specimen, $u_{\text {ext, }}$, were recorded in time.

Fracture toughness was determined on SENB specimens of dimensions: $8 \times 16 \times 64 \mathrm{~mm}\left(\mathrm{a}_{0} / \mathrm{W}=0.5\right)$ on MTS-250 testing machine, equipped with the automated control system and results recording. The $a_{0}$ is crack length, which include notch and fatigue pre-crack. The planes a $a_{0}$ are placed according to A1-A4.

Tests at the minus temperatures were performed in a thermal chamber in the evaporated nitrogen environment. Accuracy 
of maintaining the set temperature during test was $\pm 0.5^{\circ} \mathrm{C}$. During fracture toughness determination the load signal, $P$, specimen diffraction at the load point, $u_{\text {ext, }}$ crack opening $u_{C O D}$ and potential change, $U$ were recorded in time. Critical value of fracture toughness was determined according to the ASTM E1820-05 (2000).

(a)

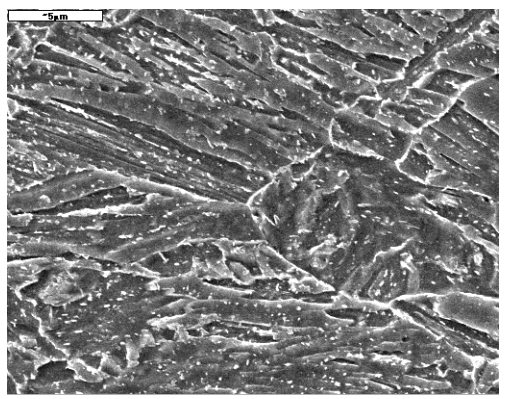

(b)

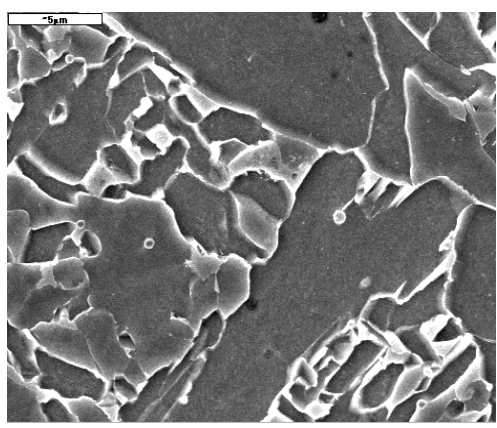

(c)

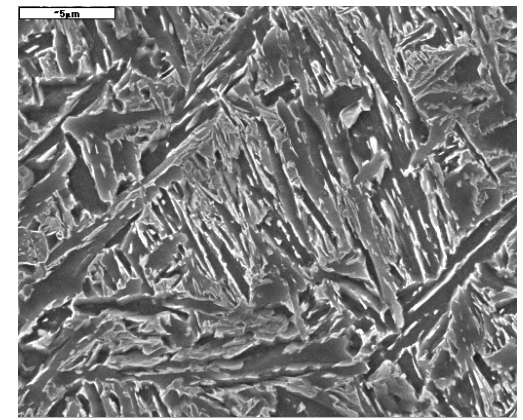

Fig. 1. Microstructure: a) - base material; b) - weld material in joint $A$; c) - weld material in joint $B$

(a)

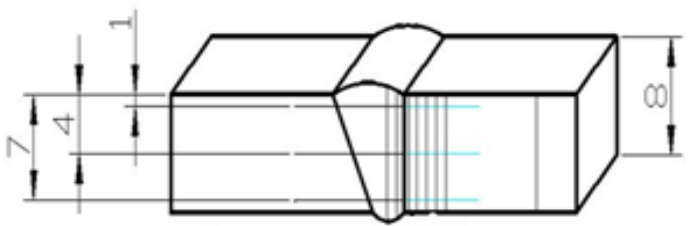

(b)

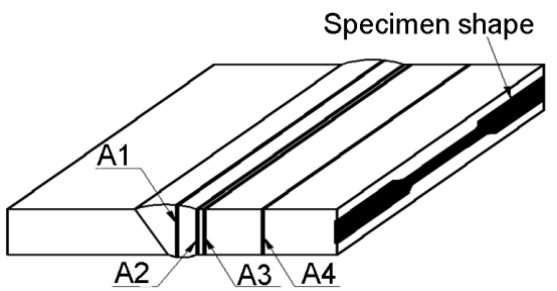

Fig. 2. Schemes: a) of hardness measuring in the cross- section of the joint; $b$ ) - of selecting the specimens to determine strength characteristics from the joint zones
In the case of ductile fracture mechanism, the critical value of $\mathrm{J}$ integral, $\mathrm{J}_{\mathrm{c}}$, was determined on a single specimen using of the potential change method to determine the crack growth and

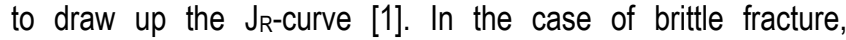
preceded by plasticity area in front of the crack tip, the critical value of the $\mathrm{J}$ integral was calculated according to the formula:

$$
\mathrm{J}_{\mathrm{C}}=\frac{2 \mathrm{~A}_{\mathrm{C}}}{\mathrm{B}\left(\mathrm{W}-\mathrm{a}_{0}\right)}
$$

In eq. (1) $A_{c}$ is deformation energy at the moment of cracking, calculated on a basis of the graph $P=f\left(u_{\text {ext }}\right)$.

The critical values $J_{c}$ were converted into units of the stress intensity factor:

$$
K_{J C}=\sqrt{\frac{J_{C} E}{\left(1-v^{2}\right)}}
$$

where: $E$ is Young's modulus, $v$ - is Poisson's ratio.

\section{TESTS RESULTS}

The hardness distribution for joints with linear welding energy (LWE) $1.2 \mathrm{~kJ} / \mathrm{mm}$ is shown in figure $3 \mathrm{a}$. The lowest hardness $(\sim 170 \mathrm{HV} 10)$ is observed in the weld material. With increasing distance from the axis of the weld hardness gradually increases reaching a value of 360-370 HV10 in the base material. In the joint of $L W E=0.7 \mathrm{~kJ} / \mathrm{mm}$, weld material hardness is close to the level of the weld material (Fig. 3b). The minimum level of hardness ( 250 HV10) was recorded in the material HAZFL. Next, with increasing distance from the axis of the weld showed a gradual increase in hardness of the material to a level corresponding to the base material. Vertical lines marked the place, where the notches are made in the SENB specimens for determining fracture toughness. From these places also were cut out the flat specimens to determine the strength characteristics (sch. 2b).

(a)

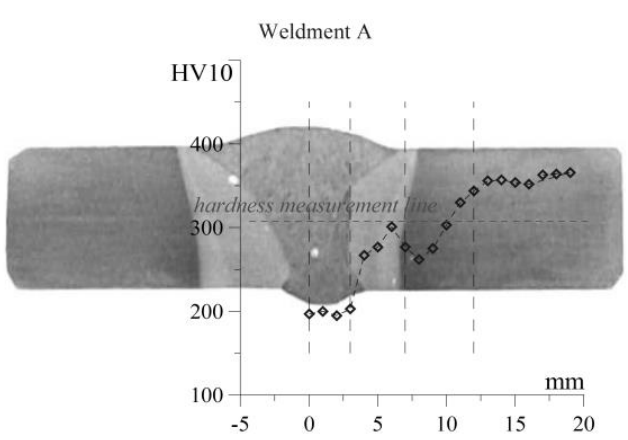

(b)

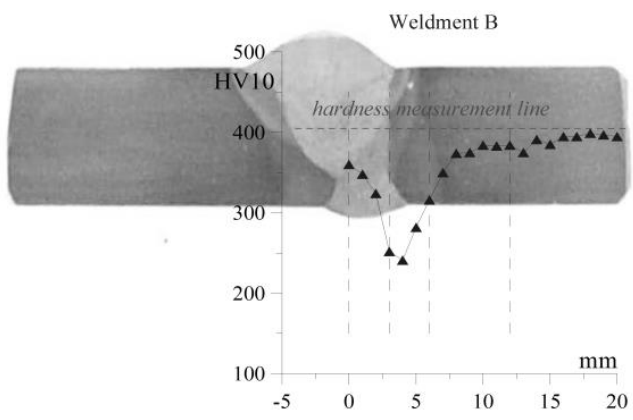

Fig. 3. Hardness distributions of the welded joints $A(a)$ and $B(b)$ 
The change of hardness in the thickness direction of the joints $A$ and $B$ are shown in the fig. 4. In the weld material of the joint $A$ hardness increases slightly from the face to the root (Fig. 4a). In the zone with distance $8 \mathrm{~mm}$ from the axis of the weld the nature of the hardness change is not regular. In the zones which are located at a distance from the axis of $8-18 \mathrm{~mm}$, the hardness value remains approximately constant at thickness, and increases along with the distance from the weld. At a distance of more than $18 \mathrm{~mm}$ from the weld axis a significant change in hardness was not observed, indicating no thermal effect on the base material.

In the joint $B$ hardness distributions in the weld material are comparable to the base material (Fig. 4b). The lowest level of hardness was observed in the material near the fusion line. Next, as the distance from the weld, hardness in areas increases and at $10 \mathrm{~mm}$ reaches a level appropriate to the base material.

(a)

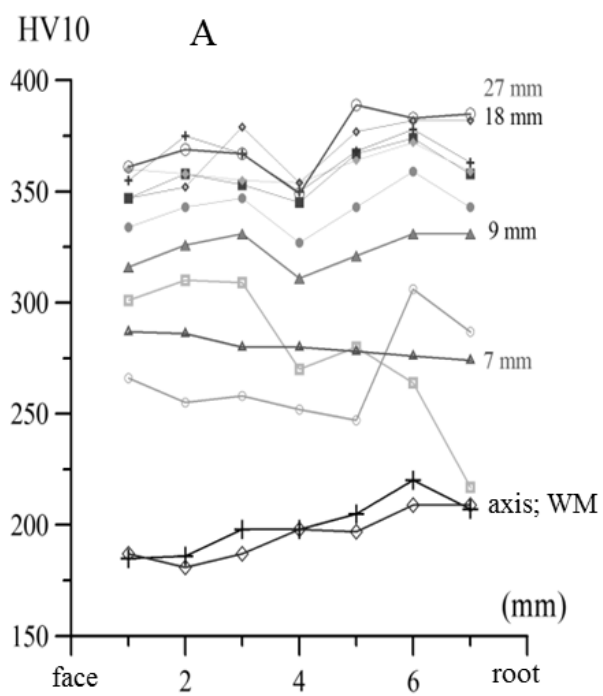

(b)

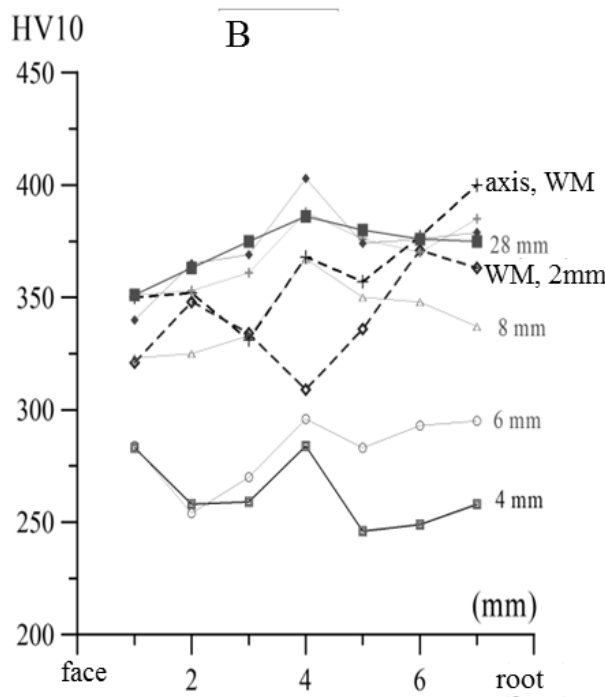

Fig. 4. Distribution of hardness in the thickness direction:
(a) joint $A$; (b) joint $B$

The measurements of hardness helped to establish the width of the heat affected zone in the joints: in the joint $A(L W E=1.2$ $\mathrm{kJ} / \mathrm{mm})$ it is twice more than in the joint $B(L W E=0.7 \mathrm{~kJ} / \mathrm{mm})$. Measurements of hardness allowed to determine in the joints the zones of low hardness, which is expected to be a low level of strength characteristics. On the basis of hardness measurements were selected areas, in which mechanical properties and fracture toughness would determined.

For the joint $\mathrm{A}$ (LWE $=1.2 \mathrm{~kJ} / \mathrm{mm}$ ) the lowest yield stress, $R_{e}$, and ultimate strength, $R_{\mathrm{m}}$, at the same time of the highest elongation value, $\varepsilon\left(R_{m}\right)$, obtained in the weld material (Tab. 2). In the following zones the strength characteristics values of $R_{e}$ and $R_{\mathrm{m}}$ increase, and the level of $\varepsilon\left(R_{\mathrm{m}}\right)$ decreases. In the case of the joint $B$, (LWE $=0.7 \mathrm{~kJ} / \mathrm{mm})$ the lowest level of strength characteristics, $R_{\mathrm{e}}$ and $R_{\mathrm{m}}$, and the highest $\varepsilon\left(\mathrm{R}_{\mathrm{m}}\right)$ has HAZFL material (Table 2). For WM, HAZN level of $R_{e}$ and $R_{\mathrm{m}}$ increases, and $\varepsilon\left(R_{m}\right)$ - decreases. The highest levels of $R_{e}$ and $R_{m}$ at the lowest $\varepsilon\left(R_{m}\right)$ in both joints correspond to the HAZE material. The results shown in Tab. 2 demonstrate that the welding regime $B$ allows to higher strength characteristics of material for all areas of joint, than the of regime $A$.

Tab. 2. The mechanical properties of welded joints materials

\begin{tabular}{|c|c|c|c|c|c|c|c|c|c|}
\hline \multicolumn{2}{|c|}{} & \multicolumn{8}{|c|}{ Linear welding energy } \\
\cline { 3 - 10 } \multicolumn{2}{|c|}{} & \multicolumn{7}{|c|}{ A: LWE=1.2 kJ/mm } & \multicolumn{4}{c|}{ B: LWE $=0.7 \mathrm{~kJ} / \mathrm{mm}$} \\
\hline Joint zone & BM & WM & HAZFL & HAZN & HAZE & WM & HAZFL & HAZN & HAZE \\
\hline$E,(\mathrm{GPa})$ & 185 & 190 & 192 & 193 & 190 & 178 & 187 & 185 & 191 \\
\hline$R_{e},(\mathrm{MPa})$ & 1005 & 535 & 607 & 670 & 1125 & 850 & 678 & 963 & 1183 \\
\hline$R_{\mathrm{m}},(\mathrm{MPa})$ & 1090 & 667 & 728 & 862 & 1180 & 1090 & 912 & 975 & 1208 \\
\hline$n$ & 55 & 13.3 & 16.37 & 13.16 & 85 & 14.2 & 11.33 & 123 & 111 \\
\hline$\varepsilon\left(\mathrm{R}_{\mathrm{m}}\right),(\%)$ & 3.1 & 16 & 8.5 & 5.8 & 2.5 & 5.1 & 6.2 & 2.7 & 2.2 \\
\hline
\end{tabular}

Dependency of strength characteristics changes of $R_{\mathrm{e}}$ and $R_{\mathrm{m}}$ on hardness are shown in the Fig. 5. Based on the dependencies, which shown in the Fig. 5, one can evaluate the level of strength characteristics in every area of the welded joint with just the measurement of hardness.

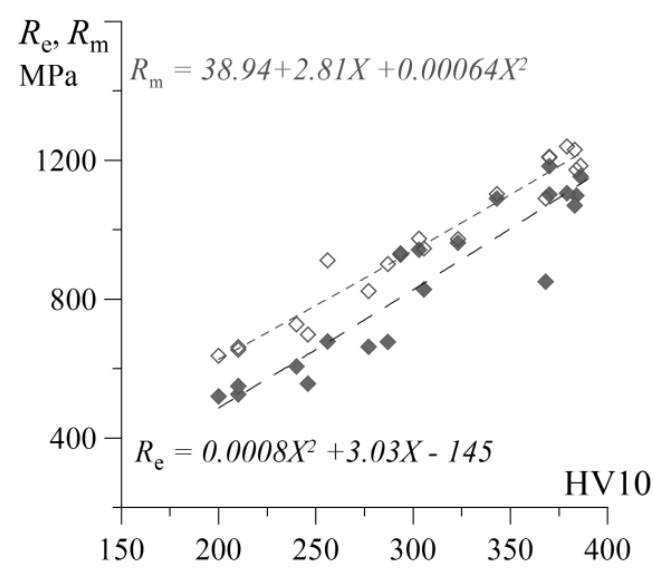

Fig. 5. The change of strength characteristics on hardness

Depending on the critical values of fracture toughness $K_{\mathrm{Jc}}$ of test temperature for the material from different weld joints $A$ and $B$ shown in Figs. $6 a$ and $6 b$, and for the base material in Fig. $6 c$. At room temperature the weld material in the joint $A$, with microstructure of fine ferrite (Fig. 1b), has high fracture toughness ( 300 MPam $^{1 / 2}$, Fig. 6a). 
(a)

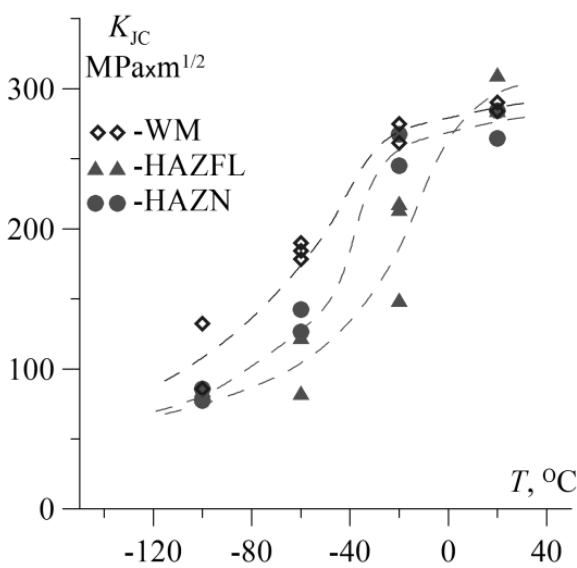

(b)

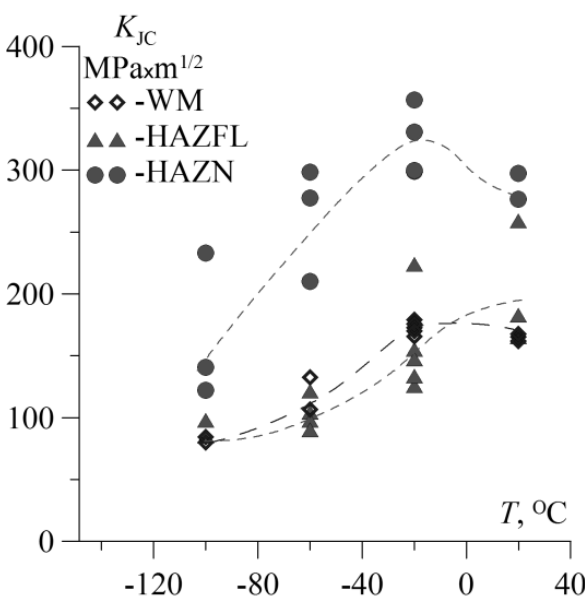

(c)

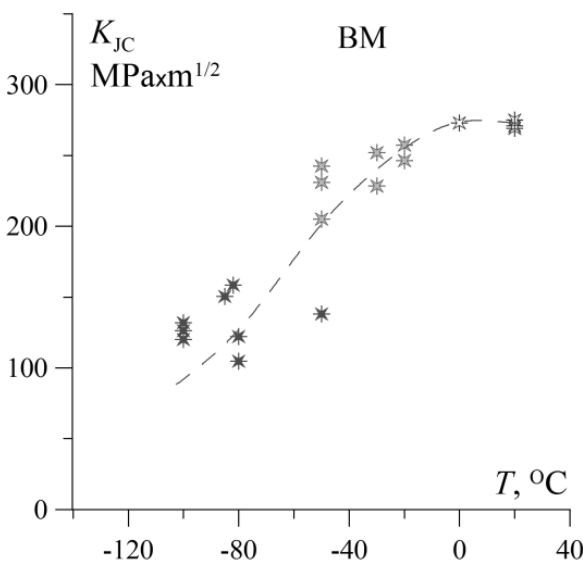

Fig. 6. Kuc dependency on the test temperature of different joints zones $A(a), B(b)$, and BM (c)

Along with the lowering test temperature the fracture toughness WM also decreases, although always maintains the highest level of fracture toughness as compared to the material of the other joint zone A (Fig. 6a). The lowest level of fracture toughness is for the HAZFL material, especially at minus temperatures. At minus test temperatures were observed high scatter of the fracture toughness critical values in this material.

For the joint $B$, the lowest level $K_{J c}$ is also present in the HAZFL material (Fig. 6b). Fracture toughness of WM in the $B$ joint (with martensite microstructure (Fig. 1C)), is generally lower than in WM of $A$ joint. The greatest difference was observed for tests at $20{ }^{\circ} \mathrm{C}$. Along with lowering the temperature, the difference in $K_{J c}$ level for the WM of the joint $A$ and $B$ disappears. In the HAZN material of the joint $B$, registered a high $K_{\mathrm{Jc}}$ level, which exceeds the $K_{\mathrm{Jc}}$ values for HAZN of the joints $A$ and BM (Fig. 6a, 6b, 6c). The fracture toughness increase, which occurs in the HAZN material of the joint $B$ in comparison to the BM, can be carried out as a result of favorable parameters of tempering bainitemartensite microstructure BM (Bhadeshia, 2001; Dzioba, 2010).

\section{SUMMARY}

The mechanical properties and fracture toughness of the material from the different zones of welded joints made of highstrength ferritic steel was determined. Welding with higher LWE $=1.2 \mathrm{~kJ} / \mathrm{mm}$ leads to a formation of a fine-grained ferritic microstructure in WM of strength characteristics level $\sim 0.5 R_{e}$ and $0.5 R_{\mathrm{m}}$, relative to $\mathrm{BM}$. Fracture toughness of $\mathrm{WM}$ is a bit higher than BM. Welding of the lower LWE $=0.7 \mathrm{~kJ} / \mathrm{mm}$ leads to the formation of the martensite microstructure in the WM of strength characteristics level $\sim 0.85 R_{\mathrm{e}}$ and $0.85 R_{\mathrm{m}}$, relative to $\mathrm{BM}$. However, fracture toughness in this case is low: $0.5 \mathrm{~K}_{\mathrm{Jc}} \mathrm{BM}$ for temperature $[-60 \div 20]^{\circ} \mathrm{C}$ and $0.8 \mathrm{~K}_{\mathrm{JC}} \mathrm{BM}$ for $T=-100{ }^{\circ} \mathrm{C}$.

The weakest link in terms of fracture toughness in both joints is HAZFL material. Lower boundaries of the scattered data of $\mathrm{KJC}_{\mathrm{JC}}$ for the HAZFL material in both joints are similar for $T \leq-20^{\circ} \mathrm{C}$. Nevertheless, the fracture toughness of the joint $A$ and $B$ is comparable, the level of the strength characteristics is higher in the joint $B$, which indicates that generally the joint $B$ is better. Tensile tests carried out on specimens without notches with joints $A$ and $B$ showed, that the joint $B$ strength is higher of $~ 15 \%[5]$.

\section{REFERENCES}

1. ASTM E 1820-05. (2000), Standard Test Method for Measurement of Fracture Toughness, ASTM; Philadelphia.

2. Bhadeshia H.K.D.H. (2001), Bainite in Steels, Institute of Materials, London.

3. Dzioba I. (2010), Properties of the 13HMF steel after operation and degradation under laboratory conditions, Materials Science, 46 (3), 357-364

4. FITNET. (2008), Fitness - for - Service. Fracture - Fatigue - Creep - Corrosion, Edited by M. Koçak, S. Webster, J.J. Janosch, R.A. Ainsworth, R. Koerc).

5. Gałkiewicz J., Pała T., Dzioba I. (2012), Strength properties of the welded joints made from high-strength ferritic steels, XXIII Symposium: Fatigue and Fracture Mechanics, Bydgoszcz Pieczyska, $63-72$ (in Polish).

6. Neimitz A., Dzioba I., Graba M., Okrajni J. (2008), Assessment of the strength, durability and safety of the structural components containing defects, Kielce University of Technology (in Polish).

7. Porter D. (2006), Developments in hot-rolled high strength structural steel, Nordic welding conference 06, New trends in welding technology, Tampere, Finland.

8. Tasak E., Ziewiec A. (2006), Welded joint structure of low-carbon and low-alloy steels, Welded Review 11/2006, 7-12 (in Polish).

The work was carried out in the framework of the cooperation between Rautaruukki Corporation, Finland and the Department of Machine Design Fundamentals, Kielce University of Technology, Poland. 